\title{
LOCAL APPLICATION OF A GENTAMICIN-LOADED THERMO- RESPONSIVE HYDROGEL ALLOWS FOR FRACTURE HEALING UPON CLEARANCE OF A HIGH STAPHYLOCOCCUS AUREUS LOAD IN A RABBIT MODEL
}

\author{
G.-J.A. ter Boo ${ }^{1,2}$, T. Schmid ${ }^{1}$, I. Zderic ${ }^{1}$, D. Nehrbass ${ }^{1}$, K. Camenisch ${ }^{1}$, R.G. Richards ${ }^{1}$, D.W. Grijpma ${ }^{2}$, \\ T. F. Moriarty ${ }^{1}$ and D. Eglin ${ }^{1}$ \\ ${ }^{1} \mathrm{AO}$ Research Institute Davos, Davos, 7270, Switzerland \\ ${ }^{2}$ MIRA Institute for Biomedical Technology and Technical Medicine, Department of Biomaterials \\ Science and Technology, University of Twente, Enschede, 7522, the Netherlands
}

\begin{abstract}
Antibiotic-loaded biomaterials (ALBs) have emerged as a potentially useful adjunctive antimicrobial measure for the prevention of infection in open fracture care. A biodegradable thermo-responsive poly $(\mathrm{N}-$ isopropylacrylamide) grafted hyaluronic acid $(\mathrm{HApN})$ hydrogel loaded with gentamicin has recently been shown to prevent implant-related infection in a rabbit osteosynthesis model. The primary aim of this study was to determine the influence of this HApN hydrogel on bone healing at an early stage (4 weeks). A rabbit humeral osteotomy model with plating osteosynthesis was used to compare fracture healing in rabbits receiving the hydrogel as compared with control animals. The secondary aim was to observe fracture healing in groups treated with and without antibiotic-loaded hydrogel in the presence of bacterial contamination. In all groups, outcome measures were mechanical stability and histological score, with additional quantitative bacteriology in the inoculated groups.

Application of the HApN hydrogel in non-inoculated rabbits did not significantly influence humeral stiffness or histological scores for fracture healing in comparison to controls. In the inoculated groups, animals receiving the bacterial inoculum without hydrogel were culture-positive at euthanasia and found to display lower humeral stiffness values and higher histopathological scores for bacterial presence in comparison with equivalents receiving the gentamicin-loaded $\mathrm{HApN}$ hydrogel, which were also infection-free.

In summary, our data showed that $\mathrm{HApN}$ was an effective antibiotic carrier that did not affect fracture healing. This data supported its suitability for application in fracture care. Addition of osteopromotive compounds could provide further support for accelerating fracture healing in addition to successful infection prophylaxis.
\end{abstract}

Keywords: Biomaterial-associated infection, prophylaxis, thermo-responsive hydrogel, fracture healing, Staphylococcus aureus.

*Address for correspondence: D. Eglin, AO Research Institute Davos, AO Foundation, Clavadelerstrasse 8, Davos, 7270, Switzerland.

Telephone: $+41814142480 \quad$ Fax: $+41814142288 \quad$ Email: david.eglin@aofoundation.org

Copyright policy: This article is distributed in accordance with Creative Commons Attribution Licence (http://creativecommons.org/licenses/by-sa/4.0/).

\section{Introduction}

Infection is one of the most common complications associated with operative fracture fixation (Darouiche, 2004; Metsemakers et al., 2015; Trampuz and Zimmerli, 2006; von Eiff et al., 2005). As the number of patients receiving implants increases annually (Darouiche, 2001), the number of implant-associated infections is also set to rise. Systemic administration of prophylactic antibiotics is shown to reduce the occurrence of infections in the primary fracture fixation of both closed (Boxma et al., 1996) and open fractures (Gosselin et al., 2004) in comparison with placebo or no antibiotic treatment. The occurrence of infections, despite prophylactic antibiotic administration, indicates that systemic antibiotic prophylaxis is not always completely effective. The failure of systemic antibiotic therapy may be due to compromised vasculature, tissue destruction and oedema limiting antibiotic penetration into 
the wound, when applied intravenously (Boxma et al., 1996; Gosselin et al., 2004). The delivery of antibiotics directly to the intended site of action using antibiotic-loaded biomaterials (ALBs) is an attractive option that may overcome this problem (ter Boo et al., 2015). Degradable ALBs, such as hydrogels, offer advantages over some of the conventional ALBs, such as antibiotic-loaded bone cement beads or spacers, due to the need for surgical removal of the latter.

Hyaluronic acid (HA) derivatives are widely used as injectable and degradable carriers for drug delivery (Oh et al., 2010; Tripodo et al., 2015). A thermo-responsive hydrogel formulation of a HA derivative loaded with gentamicin is previously described by our group (ter Boo et al., 2016). The physically crosslinked hydrogel is composed of HA, a linear polysaccharide that degrades enzymatically in the body (Aya and Stern, 2014; Fraser et al., 1997), and short chains of grafted polyacrylamide. This hydrogel is injectable, gelates both in vitro and in vivo and shows an in vitro release of gentamicin that lasts for $5 \mathrm{~d}$ upon an initial burst. In a rabbit model of fracture fixation, the antibiotic-loaded hydrogel successfully prevents bacterial infection measured 1 week after fixation (ter Boo et al., 2016). Although previous in vivo work has shown the efficacy of the gentamicin-loaded poly( $N$-isopropylacrylamide) grafted hyaluronic acid (HApN) hydrogel, the fate and the influence of the HApN hydrogel on bone healing remains unclear (ter Boo et al., 2016).

A concern for any ALB that might be added directly to a fracture site is that it may interfere with the fracture healing. The foreign material itself, the time to degrade and the effect of high local concentrations of antibiotics may potentially influence healing of the tissues (Isefuku et al., 2003; Rathbone et al., 2011). Few reports are available on bone healing after delivery of antibiotics by a biodegradable ALB and clearance of a bacterial load (Ferguson et al., 2014; McLaren et al., 2014; Stewart et al., 2010). To our knowledge, no previous in vivo studies, involving bone healing in the presence of an ALB, include quantitative measures of bone healing, such as bending stiffness. In particular, bone healing data in the context of antibiotic release and material degradation profiles matching our HA thermo-responsive hydrogel are lacking.

In this study, the effect of the injectable thermoresponsive physical crosslinked HA hydrogel on the bone healing process was assessed in vivo. The rabbit humeral osteotomy model with plating osteosynthesis developed by Arens et al. (2015) was used, as it represents a realistic simulation of fracture healing after trauma, by incorporating many of the factors that might influence bone healing or occurrence of an infection (i.e. antibiotics, bacteria, fracture and implant). Fracture healing in sterile wounds was compared between animals healing with only the fixation implant and rabbits treated with HApN injected after implant placement.

Haematological and clinical observations of the rabbits were performed throughout the 4 -week observation period. Additionally, fracture healing in rabbits receiving bacterial inocula with or without gentamicin-loaded HApN was evaluated. Quantitative bacterial infection and potential foreign body reactions were evaluated. Fracture healing in animals receiving the hydrogel versus controls, both with and without bacterial inoculation, was compared at week 4. Quantitative and semi-quantitative outcome measures to assess new bone formation were given by four-point bending mechanical testing, X-ray analysis and histological scores.

\section{Materials and Methods}

\section{Materials}

Hyaluronic acid sodium salt (HANa) from Streptococcus equi, number-average molecular weight $\left(M_{n}\right)=170.6 \mathrm{kDa}$ and polydispersity $\left(\mathrm{M}_{\mathrm{n}} / \mathrm{M}_{\mathrm{w}}\right)=1.73$, was purchased from Contipro Biotech s.r.o. (Dolni Dobrouc, Czech Republic). Tetrabutylammonium hydroxide solution $(\mathrm{TBAOH})\left(\approx 40 \%\right.$ in $\mathrm{H}_{2} \mathrm{O}$, $\approx 1.5 \mathrm{~mol} / \mathrm{L}), 2,2$ '-azobis(2-methylpropionitrile) (AIBN) ( $\geq 98.0 \%$ by gas chromatography), methanesulphonic acid (MSA) ( $\geq 99.5 \%)$, methanol [analytical grade $(99.8 \%)$ ] and ethanol ( $\geq 99.8 \%$ purity) were purchased from Fluka (Buchs, Switzerland). $N$-isopropylacrylamide (nIPAm) ( $\geq 99 \%)$, cysteamine hydrochloride (AESH) [ $\geq 98 \%$ (titration) $], N, N-$ dimethylformamide (DMF) anhydrous (99.8\%), 1,4-dioxane $(\geq 99.5 \%)$, deuterium oxide $\left(\mathrm{D}_{2} \mathrm{O}\right)(99.9$ atom \% D), Dowex M-31 cation exchange resin, $1,1^{\prime}$-carbonyldiimidazole (CDI) (reagent grade), dimethyl sulphoxide (DMSO) ( $\geq 99.5 \%$ for synthesis), gentamicin sulphate salt (Gen) (potency $\geq 590 \mu \mathrm{g}$ gentamicin base per mg) and phosphate-buffered saline (PBS) were purchased from Sigma-Aldrich (St. Louis, MO, USA). Diethylether ( $\geq 99.5 \%)$, glycerol $(\geq 99 \%)$ and sodium bromide $(\mathrm{NaBr})(\geq 99 \%)$ were purchased from Carl Roth (Karlsruhe, Germany). Blood agar (BA), tryptone soya agar (TSA), tryptic soy broth (TSB) and Mueller-Hinton broth (MHB) were purchased from Oxoid AG (Basel, Switzerland).

\section{In vivo study design}

The rabbit humeral osteotomy model with plating osteosynthesis, developed by Arens et al. (2015), was used. Four study groups were included, as shown in Table 1 . The primary comparison was osteotomy healing in the absence (group 1) or presence (group 2) of HApN in non-inoculated animals. The secondary comparison was osteotomy healing in the absence (group 3) or presence (group 4) of gentamicin-loaded $\mathrm{HApN}$ in rabbits receiving the bacterial inoculum.

\section{Preparation of gentamicin-loaded thermo- responsive hydrogel}

Amino-terminated poly( $N$-isopropylacrylamide) $\left(\mathrm{pN}-\mathrm{NH}_{2}\right)$ was prepared and characterised with respect to its molecular weight, as described previously (ter Boo et al., 2016). The molecular weight 
Table 1. List of the in vivo study groups, including presence of inoculum, thermo-responsive hydrogel and gentamicin sulphate. $n=10$ per study group. Target inoculum was $2.0 \times 10^{6} \mathrm{CFU}$ per rabbit. Volume of HApN hydrogel applied was $800 \mu \mathrm{L}(13 \% \mathrm{w} / \mathrm{w})$ per rabbit. Total payload of gentamicin sulphate in the hydrogel was $8 \mathrm{mg}$ per rabbit.

\begin{tabular}{|l|c|c|c|}
\hline Group name & S. aureus & HApN & Gentamicin sulphate \\
\hline Non-inoculated control & - & - & - \\
\hline Non-inoculated + HApN & - & + & - \\
\hline Inoculated control & + & - & + \\
\hline Inoculated + HApN Gen & + & + & - \\
\hline
\end{tabular}

$\left(\mathrm{M}_{\mathrm{n}}\right)$ of the $\mathrm{pN}-\mathrm{NH}_{2}$ obtained was $21.2-21.4 \mathrm{~kg} / \mathrm{mol}$, with a polydispersity index $\left(\mathrm{M}_{\mathrm{w}} / \mathrm{M}_{\mathrm{n}}\right)$ between 2.32 and 2.63. For the synthesised $\mathrm{pN}-\mathrm{NH}_{2}$, the recovered mass was between $82.2 \%$ and $83.4 \%$. The two batches synthesised under the same condition were used in the synthesis of two HApN batches.

$\mathrm{NaHA}$ was converted into its tetrabutyl ammonium salt (HATBA) by a cationic exchange process, as described by Bellini and Topai (Bellini and Topai, 2000). Subsequently, $\mathrm{pN}-\mathrm{NH}_{2}$ was grafted to the HATBA in a direct amidation reaction (ter Boo et al., 2016). Then, the degree of substitution of $\mathrm{pN}$ $\mathrm{NH}_{2}$ for the carboxyl group on the HA backbone was determined by proton nuclear magnetic resonance $\left({ }^{1} \mathrm{H}-\mathrm{NMR}\right)$ by integration of the HA proton NMR signals between $\delta=3.00 \mathrm{ppm}$ and $3.77 \mathrm{ppm}$, equivalent to 9 protons belonging to the HA dimer and integration of the $\mathrm{pN}$ signal at $\delta=1.14 \mathrm{ppm}$, deriving from 6 protons on the two methyl groups of $\mathrm{pN}$ (D'Este et al., 2012). The degree of grafting of $\mathrm{pN}$ to HA for the HApN batches used in this study was calculated to be $11-12 \%$. Sterilisation was performed using low temperature ethylene oxide, as previously reported (ter Boo et al., 2016).

\section{In vivo study}

The in vivo study was approved by the Ethical Committee of the Canton of Grisons, Switzerland (TVB numbers 2015_06F and 2015_13E). All procedures were performed in an AAALAC- (Association for Assessment and Accreditation of Laboratory Animal Care International) approved facility and according to Swiss animal protection law and regulations. 40 skeletally mature, specific pathogen-free (SPF) female New Zealand white rabbits (Charles River Laboratories International, Inc, Sulzfeld, Germany) older than 24 weeks and with a mean body weight of $3.9 \pm 0.4 \mathrm{~kg}$ were included in this study.

\section{Animal welfare}

All rabbits were assessed by a veterinarian and determined to be healthy prior to inclusion in this study. Rabbits were group-housed and allowed to acclimatise to their surroundings for 2 weeks prior to the start of the study. After the surgical intervention, animals were single-housed until euthanasia. After surgery, each animal was checked at least twice daily for the first 5 post-operative days by a veterinarian or an experienced animal care taker. Thereafter, the animals were checked once daily at day 6 and 7 after surgery and twice a week for the rest of the study. 2 rabbits had to be excluded during anaesthesia due to cardiac arrest and 3 rabbits had to be excluded during the observation period due to a fracture of the operated bone. All the 5 excluded rabbits were replaced.

\section{Pre-operative bacterial inoculum and hydrogel preparation}

A gentamicin-sensitive clinical Staphylococcus aureus (S. aureus) (JAR 060131) isolate was used in the present study (Campoccia et al., 2008). Bacteria were stored in MHB supplemented with $20 \%$ glycerol for long term preservation at $-20{ }^{\circ} \mathrm{C}$. Bacterial inocula were prepared in PBS as previously described (Moriarty et al., 2010; ter Boo et al., 2016), with a target inoculum of $2.0 \times 10^{6}$ colony forming units (CFU) of S. aureus. Quantitative culture of each inoculum was performed immediately after preparation to assure the accuracy of the used inocula.

$1 \mathrm{~d}$ prior to surgery, the sterile HApN samples were reconstituted at $13 \% \mathrm{w} / \mathrm{w}$. For study group 2 (non-inoculated $+\mathrm{HApN}$ ), reconstitution was in sterile PBS, whilst for study group 4 (inoculated $+\mathrm{HApN}+\mathrm{Gen})$, reconstitution was in sterile PBS containing $1 \% \mathrm{w} / \mathrm{w}$ gentamicin sulphate. The total payload of the antibiotic-loaded HApN hydrogel was $8 \mathrm{mg}$ gentamicin sulphate in $800 \mu \mathrm{L}$ of the hydrogel, which was the volume injected over the implant.

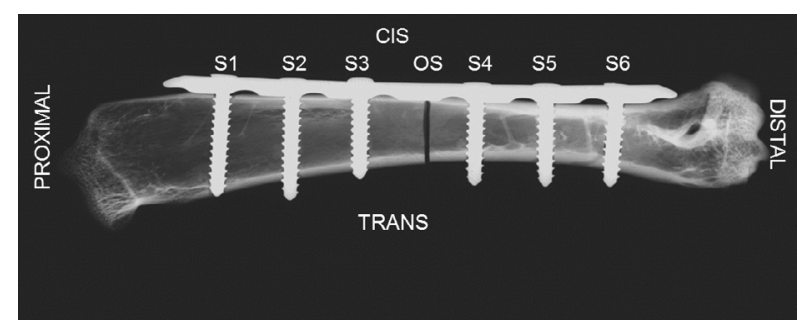

Fig. 1. Full thickness contact radiograph depicting the rabbit humerus osteotomy model, including screw positions (S1-S6) and osteotomy (OS). Inoculation was performed on top of S3, S4 and in the OS. The HApN hydrogel was applied in the osteotomy gap and on top of the fracture fixation plate and allowed to spread through the wound before gelling. 


\section{Surgical procedure}

The surgical procedure as well as anaesthesia and pre- and post-operative analgesia was performed as described previously (Arens et al., 2015). Rabbits belonging to study group 3 (inoculated control) and study group 4 (inoculated $+\mathrm{HApN}+\mathrm{Gen}$ ) received a bacterial inoculum after creation of the osteotomy. The inoculum consisted of three separate injections of $34 \mu \mathrm{L}$ of bacterial suspension into the empty screw hole overlying the osteotomy and on the head of adjacent proximal and distal screws. Rabbits belonging to study group 2 (non-inoculated $+\mathrm{HApN}$ ) received HApN hydrogel injected over the 7-hole locking plate. Rabbits of study group 4 (inoculated $+\mathrm{HApN}+$ Gen) received the gentamicin-loaded HApN hydrogel after bacteria inoculation. The wounds were closed immediately after application of the hydrogel. Fig. 1 shows a schematic overview of the rabbit humerus osteotomy model including fracture fixation hardware.

\section{Observation}

Blood samples were withdrawn from all included rabbits pre-operatively, 3 and 6 h post-operatively, then once daily until day 7 post-operatively and, later, on a weekly basis until the end of the study. White blood cell (WBC) count was measured at these time points (Vet ABC, Scil animal care, Viernheim, Germany). For the non-inoculated study groups, C-reactive protein (CRP) concentrations were quantified by enzyme-linked immunosorbent assay (ELISA) (rabbit CRP Elisa kit; ICL Inc., Portland, OR, USA) at each time point until day 7 post-operatively. Serum gentamicin levels were quantified by fluorescence polarisation immunoassay (FPIA, lower limit of detection: $0.5 \mu \mathrm{g} / \mathrm{mL}$ ) on a Cobas Integra ${ }^{\circledR}$ 400 plus analyser (Roche Diagnostics AG, Risch, Switzerland) using reagents from Roche Diagnostics. Test solutions and calibration standards were diluted with human plasma. Weight of the rabbits was measured at the time of surgery, $3 \mathrm{~d}$ and $7 \mathrm{~d}$ postoperatively and, then, weekly for the duration of the study. Radiographs of the operated limbs were taken in two planes (lateromedial and caudocranial) from all operated rabbits directly after surgery and then weekly until the end of the study. Animal exclusion criteria were: signs of systemic infection such as fever, depression and anorexia, local infection with severe lameness, persistent swelling and discharge or a weight loss exceeding $15 \%$ of the initial body weight. All rabbits were euthanised at the end of the observation period using intravenously-administered pentobarbital (Esconarkon ${ }^{\circledR}$, Streuli Pharma AG, Uznach, Switzerland).

\section{Bacteriology}

Immediately after euthanasia, the soft tissues, including all large muscles covering the implant, and any abscess material, if present, were removed using a scalpel, weighed and placed into a sterile receptacle containing $10 \mathrm{~mL}$ of PBS. As the bone was reserved for further mechanical testing and histological sectioning, no bacteriological data were acquired for this tissue. Then, the soft tissues were homogenised using an Omni-TH hand-held homogeniser (LabForce AG, Muttenz, Switzerland) with sterile Omni-tip plastic probes. All implant samples were transferred to sterile glass test tubes containing $10 \mathrm{~mL}$ of PBS. Next, implant samples were sonicated (Bandelin Ultrasonic water bath RK 510 H; Bandelin, Berlin, Germany) for $3 \mathrm{~min}$ and subsequently vortexed for $10 \mathrm{~s}$. Further processing of the samples for quantitative bacteriology was performed as previously described (ter Boo et al., 2016).

\section{Mechanical testing of rabbit humeri}

After removal of the plate and screws from the operated humeri, the bending stiffness of the bone was determined by a non-destructive four-point bending test according to ISO 9585 (1990), using a material testing machine (Instron 5866, Instron, Norwood, MA, USA) equipped with a $1 \mathrm{kN}$ load cell. Axial compression along the machine axis was applied to the bone by two loading pins of $10 \mathrm{~mm}$ in diameter, $25 \mathrm{~mm}$ apart from each other, attached to the machine actuator. With the posterior side of the humerus facing towards the machine actuator, each specimen was supported by two pins of $10 \mathrm{~mm}$ of diameter connected to the machine base, $50 \mathrm{~mm}$ apart from each other. The supporting points were defined by letting each specimen settle according to its anatomical landmarks. The setup, with a specimen mounted for biomechanical testing, is shown in Fig. 2. Prior to testing the specimens, the load necessary to fracture intact non-operated rabbit humeri was determined for cadaveric humeri of age-matched rabbits (approximately $400 \mathrm{~N}$ ). Then, both the operated humerus and the contralateral humerus of each rabbit included in the study were loaded to $100 \mathrm{~N}$ at a rate of $1 \mathrm{~mm} / \mathrm{min}$. Axial stiffness of the

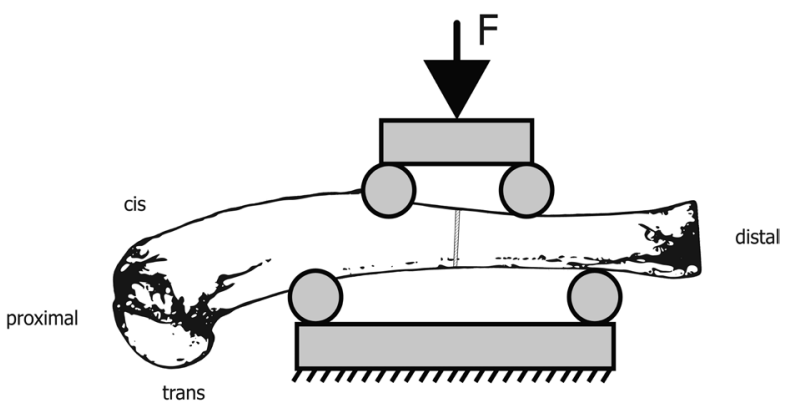

Fig. 2. Mechanical testing setup showing the positioning of the mounted operated rabbithumerus after implant removal. The distance between the two loading pins (diameter $=\varnothing=10 \mathrm{~mm}$ ) attached to the actuator was $25 \mathrm{~mm}$ and between the two loading pins $(\varnothing=10 \mathrm{~mm})$ at the machine base was $50 \mathrm{~mm}$. The relative stiffness was calculated as the stiffness of the operated humerus divided by the stiffness of the contralateral humerus of the same rabbit. 
rabbit humeri was derived from the ascending linear slope of the load-displacement curve in the interval between $50 \mathrm{~N}$ and $100 \mathrm{~N}$. Finally, the stiffness was expressed as the normalised stiffness of the operated humerus as compared to the stiffness of the intact contralateral humerus of the same rabbit.

\section{Histopathological evaluation}

Full thickness contact radiographs were taken in two planes (lateromedial and caudocranial) using high resolution technical film (D4 Structurix DW ETE, Agfa, Mortsel, Belgium) and a cabinet X-ray system (Model No. 4385A, Faxitron X-ray Corporation, Tucson, AZ, USA) to document the state of the humeri after biomechanical testing. Then, rabbit humeri were fixed in $70 \%(\mathrm{v} / \mathrm{v})$ methanol for a minimum of 2 weeks, with fresh methanol changes weekly. After fixation, samples were dehydrated through an ascending series of ethanol and transferred to xylene. Finally, the samples were infiltrated and embedded in methylmethacrylate (MMA). Polymerised MMA blocks were trimmed using a butcher saw (Bizerba FK 22, Bizerba AG,Trimms, Switzerland) and then cut in longitudinal plane using an annular diamond blade saw (Leitz 1600 saw microtome, Leica AG, Heerbrugg, Switzerland). Next, the samples were glued with cyanoacrylate onto beracryl holders for sectioning. Contact radiographs of the sections were taken as described previously (Arens et al., 2015; D'Este et al., 2016). The two sections to be stained were selected from as close as possible to the midline of the humerus, including the empty screw holes. Sections were glued onto opaque Plexiglas ${ }^{\circledR}$ slides, ground and fine-polished. One of the sections of the humeri was stained with Giemsa-eosin, the other with Brown and Brenn stains. The Giemsa-eosin-stained sections were used for semi-quantitative histopathological evaluation with a focus on tissue repair and fracture healing. Histological findings were described according to distribution, morphological character and severity using a semi-quantitative grading scheme (five-point scale) (Arens et al., 2015; D'Este et al., 2016). The Brown-and-Brenn-stained sections were used to confirm the presence of bacteria. The histopathological analysis included osteotomy gap filling, endosteal and periostal callus formation, presence of inflammation, presence of multinuclear histiocytes and presence and amount of Brown-andBrenn-positive coccoid bacteria.

\section{Statistical analysis}

Statistical evaluation was performed using IBM SPSS statistics software, version 23 (Armonk, New York, NY, USA). Data were screened for normality of distribution with the Shapiro-Wilk test. An independent $t$-test was run to compare the values of the bacterial inoculum in the two inoculated groups. One-way analysis of variance (ANOVA) test with Tukey post-hoc correction for multiple comparisons was conducted to compare the outcome measures for quantitative bacteriology data, normalised stiffness and periosteal callus formation among the four study groups. Finally, two-way ANOVA test with Tukey post-hoc correction was performed to detect significant influence of haematological values and weight change data on the four study groups. Level of significance was set at ${ }^{*} p<0.05$ for all statistical tests.

\section{Results}

\section{Prevention of infection by gentamicin-loaded HApN hydrogel at week 4}

CRP concentrations, lymphocyte/granulocyte ratio, WBC counts and weight of the rabbits in each group throughout the observation period are shown in Fig. 3. No significant weight differences were observed among the 4 rabbit study groups, during the 4-week observation period. However, there was a slight trend towards a small weight gain in rabbits from the study group 3 (inoculated control) in comparison to the other study groups. Rabbits not inoculated with bacteria and the group inoculated with bacteria in the presence of the gentamicin-loaded hydrogel (groups 1, 2 and 4) showed increasing levels of CRP that reached the maximum value $2 \mathrm{~d}$ post-operatively, after which they returned to pre-operative levels. WBC counts presented a similar pattern in groups 1, 2 and 4 , with a maximum count 3 to $7 \mathrm{~d}$ post-operatively and subsequent return to pre-operative values. The rabbits inoculated with bacteria in the absence of the hydrogel (group 3) showed a significantly higher CRP level, larger WBC count and lower lymphocyte/ granulocyte ratio than rabbits from the other study groups. WBC counts for rabbits from study group 3 remained larger throughout the whole observation period. The lymphocyte/granulocyte ratio remained significantly lower for group 3 in comparison to group 4 until day 28 (Fig. 3). Gentamicin plasma concentrations in rabbits from group 4 reached an average of $1.11 \pm 0.32 \mu \mathrm{g} / \mathrm{mL}, 3 \mathrm{~h}$ post-operatively.

In both inoculated groups (group 3 and 4 ), the total viable counts of the bacterial inocula given to each rabbit during the initial surgery are shown in Fig. 4a. There was no significant difference in the initial inocula given to the two groups. At euthanasia, 9 out of 10 rabbits receiving the inoculum, but not the gentamicin-loaded hydrogel (group 3) were found to be culture-positive for bacteria at the locations sampled (implant and overlying fibrous capsule). The only rabbit found to be culture-negative at the implant and fibrous capsule was positive for Grampositive bacteria in the Brown-and-Brenn-stained section of the bone, confirming it was indeed infected. In general, the stained sections from rabbits of the inoculated control group (study group 3) showed large amounts of Gram-positive coccoid bacteria visible in both histological stainings. Large numbers of colonies could be seen in the Giemsa-eosinstained sections (Fig. 4c,d) and additionally small amounts of bacteria could be seen in Brown-andBrenn-stained sections (Fig. 4e). Furthermore, empty 
osteocytic lacuna were observed in the cortex (focal osteonecrosis near the osteotomy) and a large amount of acellular debris was observed in the bone marrow of these rabbits, featuring a diffuse necrotising osteomyelitis (Fig. 4c). The presence of bacteria was accompanied by large numbers of inflammatory cells (Fig 4c). The implant and fibrous capsule samples of all rabbits receiving the inoculum and gentamicinloaded HApN (group 4) were culture-negative for bacteria (Fig. 4b). In the stained sections from rabbits from study group 4, bacteria were detected neither in the Giemsa-eosin- nor in the Brown-and-Brennstained sections. Signs of osteonecrosis, such as the ones observed in the sections of the inoculated control rabbits, were not observed in the histological sections from study group 4, but rather displayed a more physiological appearance (Fig. 5).

\section{Fracture healing in the presence of the HApN} hydrogel at week 4

Bone healing among groups was compared quantitatively and semi-quantitatively using mechanical testing and histopathological analysis, respectively. 4 weeks post-surgery, the normalised stiffness of the operated humeri was on average $67 \%$ of the stiffness of the contralateral humerus in the non-inoculated control group, indicating that healing had commenced, though not yet completed. When comparing the results among the groups, the mean stiffness values in the non-inoculated groups without and with HApN hydrogel showed a decrease from $67 \%$ to $49 \%$, despite not being statistically significant (Fig. 6). The relative stiffness of humeri in the inoculated control group and the inoculated $+\mathrm{HApN}$ + Gen group were $30 \%$ and $33 \%$, respectively.

Representative contact radiographs and Giemsaeosin-stained overview microphotographs of the operated humeri for each study group are shown in Fig. 5. In the non-inoculated control group (study group 1), a large amount of periosteal callus was formed around the osteotomy gap (Fig. 5,6b). Callus formed at both cis and trans sides of the bone, but predominantly on the trans side. New bone formation was also observed at the interface of the screws and the intramedullary cavity. A small amount of blue stained cartilage was observed in the osteotomy where the bone was bridging (Fig. 5). In the humeri from non-inoculated rabbits that received the HApN
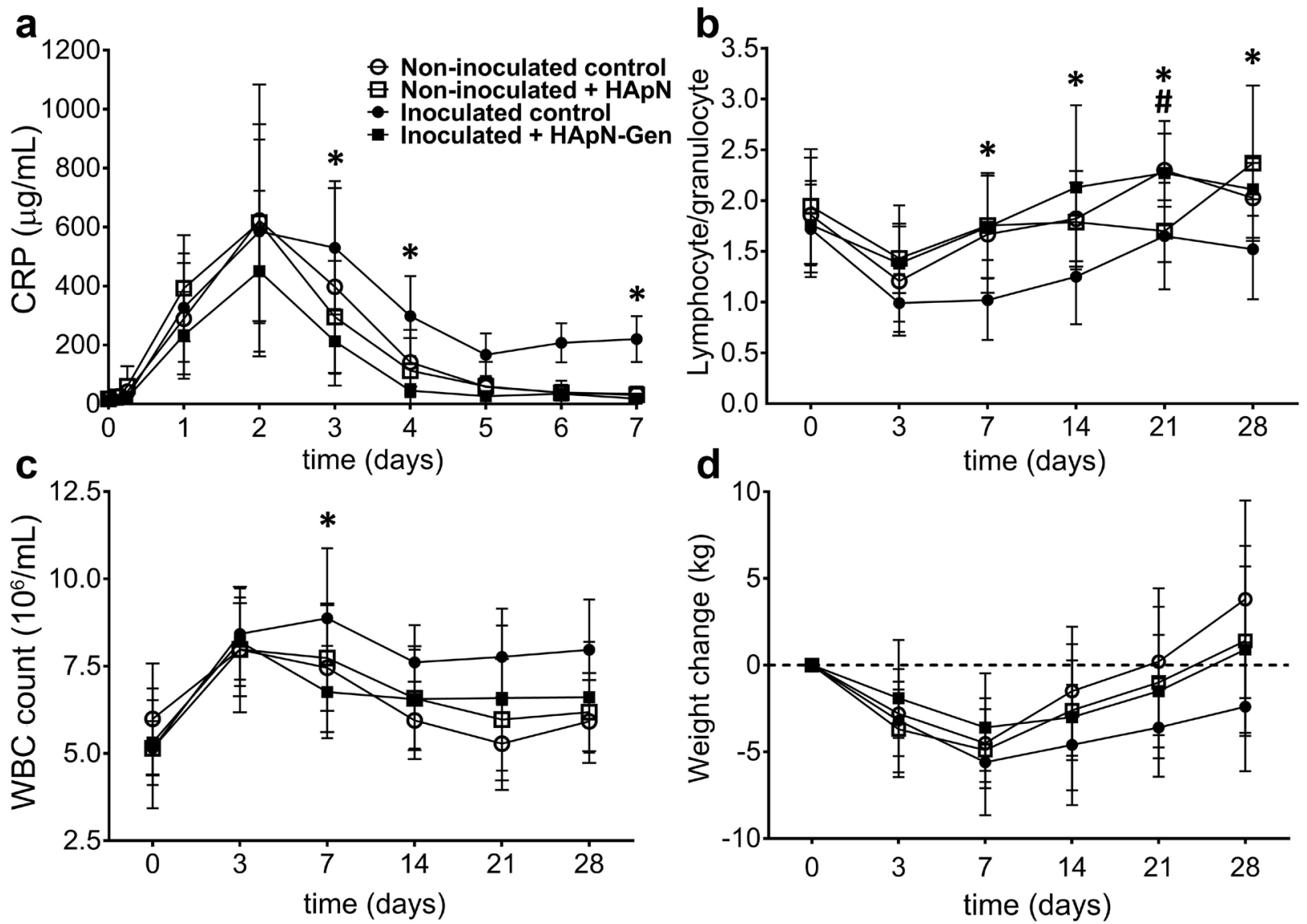

Fig. 3. Haematological and clinical observations of rabbits from non-inoculated control group (circles), noninoculated + HApN hydrogel group (squares), inoculated control group (upright triangles) and inoculated + HApN + Gen group (tip-down triangles). (a) CRP concentration in rabbit serum [CRP concentrations for the inoculated study groups are historical data included here for comparison (ter Boo et al., 2016)]; (b) ratio of lymphocytes to granulocytes; (c) WBC count; (d) weight change in comparison to pre-operative weight. Data are represented as mean \pm standard deviation (\# represents significance between the noninoculated groups 1 and 2, * represents significance between the inoculated study groups 3 and 4). 
hydrogel (study group 2), a large amount of new periosteal callus was also formed, both at the cis and the trans site of the bone, as well as at the interface between the screws and the intramedullary cavity (Fig. 5). However, the amount of endosteal and periosteal callus formation was smaller than in rabbits that only had surgery, primarily at the cis site (Fig. 6b).

In the humeri of the inoculated control group (study group 3), no callus formation was observed at the anatomical sites where the inoculation was performed (osteotomy and S3 and S4 screw holes) (Fig. 5). Large amounts of necrotic tissue were observed in the medullary cavity at the osteotomy site and at the S3 screw. Screws more distal to the inoculation points showed better osteo-integration. Gram-positive coccoid bacteria could be detected by Giemsa-eosin-staining. Humeri from rabbits that received the gentamicin-loaded hydrogel upon inoculation (study group 4) showed new callus formation and no necrotic tissue was observed. Furthermore, no bacteria could be detected. The newly formed callus was localised at the trans site of the humerus and at the interface between the screws and the intramedullary cavity, while the cis callus and the endosteal bone formation at the osteotomy site were relatively low (Fig. 5,6b). Fibrous encapsulation of the metal implant was observed in both non-inoculated study groups. The soft tissue near the osteotomy site in the inoculated control group showed acellular necrotic debris, fibrin and a mixed population of inflammatory cells due to inflammation below the plate (Fig. 5,7).

Finally, histopathological evaluation of the rabbit humeri sections also focused on any reaction to any remnants of the hydrogel components and their localisation. In the sections from the rabbits of the groups receiving the hydrogel (study group 2 and 4 ), large numbers of mono- and multinucleated histiocytes with foamy bluish cytoplasm were present, as shown in Fig. 7, indicative of ongoing HApN clearance. Cells with similar morphology were absent in the sections from the rabbits of the other study groups that did not receive the HApN hydrogel (Fig. 7).

\section{Discussion}

The aim of this in vivo study was to assess the influence of a thermo-responsive $\mathrm{HApN}$ hydrogel on bone healing in a rabbit model. Such information a

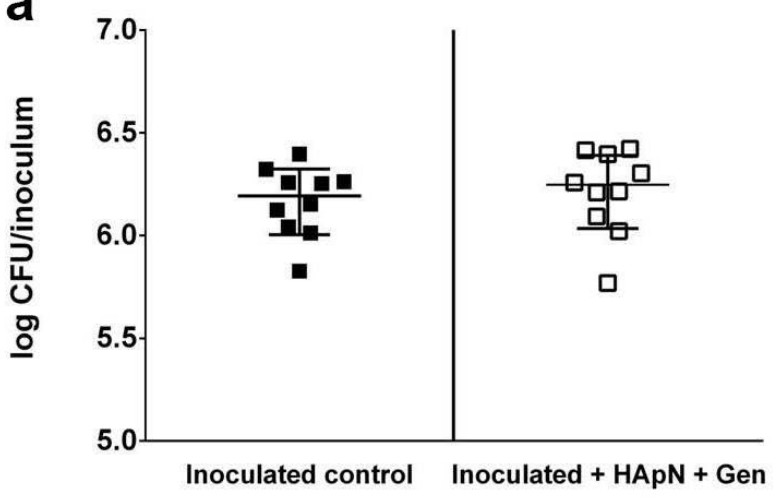

b

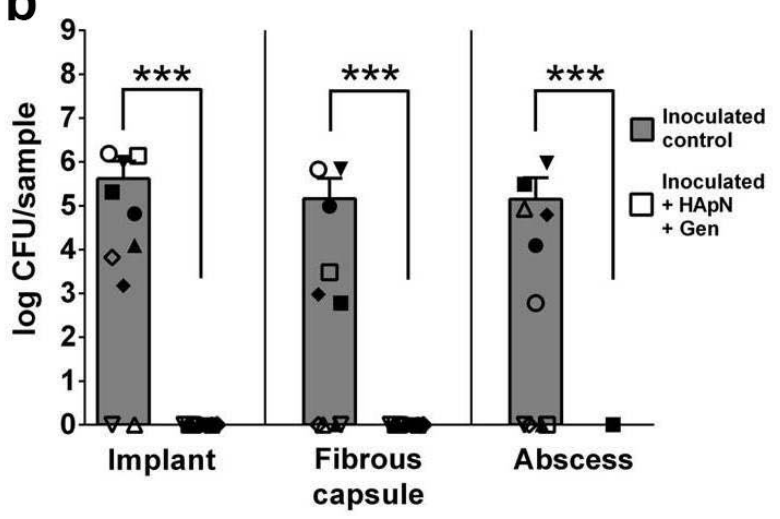

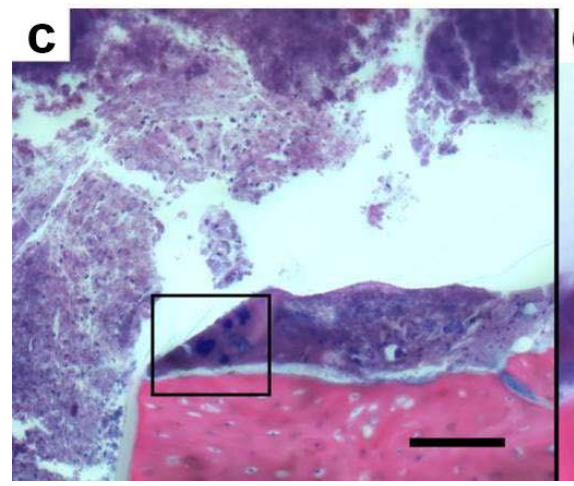
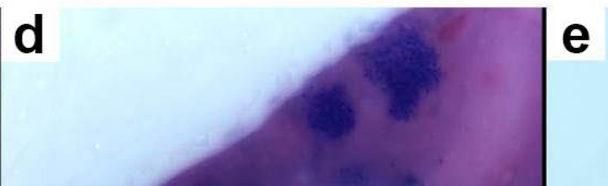

Fig. 4. (a) Pre-operative quantification of bacterial inocula used during rabbit surgeries; (b) bacterial quantification of implant, fibrous capsule and abscess material (if present), $n=10$ per study group, error bars indicate standard deviation. Each of the 10 rabbits per study group is represented by a different symbol (5 closed and 5 open symbols; ${ }^{*}$ represents significance between the inoculated study groups 3 and 4); (c,d) microphotographs of Giemsa-eosin- and (e) Brown-and-Brenn-stained humeri sections at the trans side near the osteotomy of an infected rabbit (study group 3). The blue dots visible in both Giemsa-eosin and Brown and Brenn sections are Gram-positive bacteria. d,e are close-ups (lens 100× oil, scale bar: $20 \mu \mathrm{m})$ of the area within the square in c (scale bar: $100 \mu \mathrm{m})$. 
is critical to fully evaluate the potential applicability of locally-delivered antibiotic into a fracture site. It was found that the presence of the HApN did not significantly influence bone healing: the relative stiffness and histological score of operated humeri, in which the HApN hydrogel was applied during surgery, was not significantly different from control humeri.

Bone healing in the presence of an ALB is investigated in in vivo models by Ambrose et al. (2003) and Peng et al. (2010); however, these are prophylactic studies and do not include a quantitative measure of bone healing, such as bending stiffness. The osteotomy fixation model used in this in vivo study represents a realistic simulation of fracture healing after trauma, by incorporating many of the factors that might influence bone healing, or occurrence of an infection (Arens et al., 2015). The osteotomy in this model heals within approximately 10 weeks, when not inoculated (Arens et al., 2015; Terjesen, 1984; Wang et al., 2005). In the present study, bone healing was assessed after 4 weeks, as the largest variations among the study groups were anticipated in this early bone healing phase, thus maximising
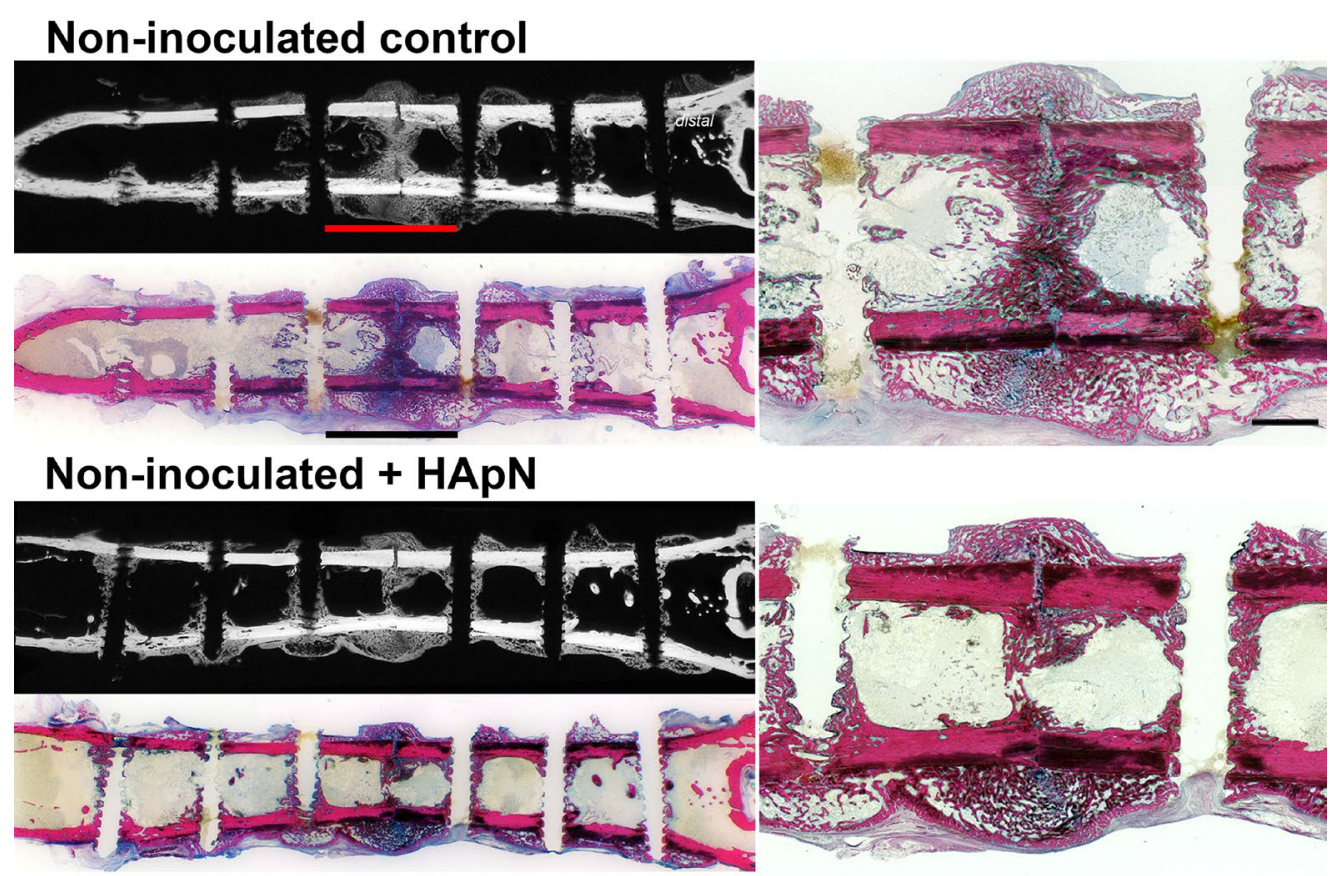

Inoculated control

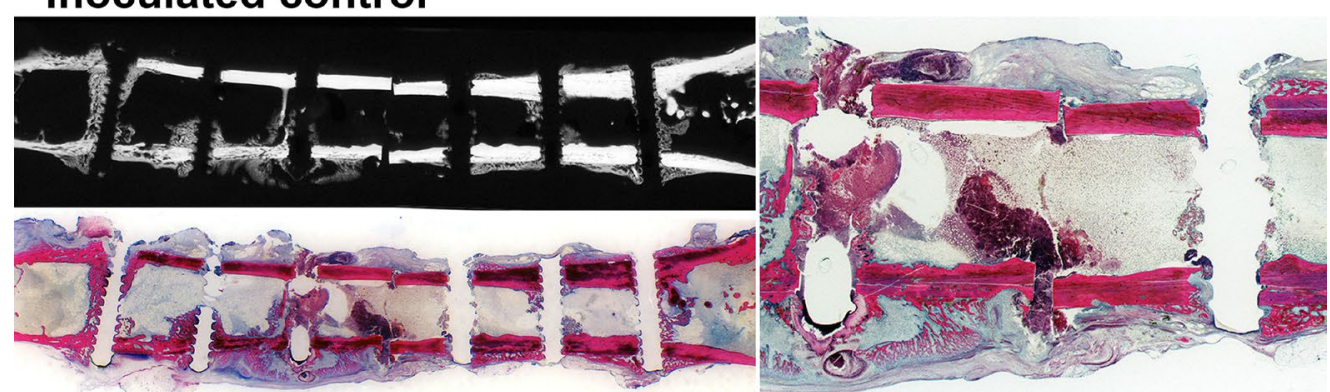

Inoculated + HApN + Gen

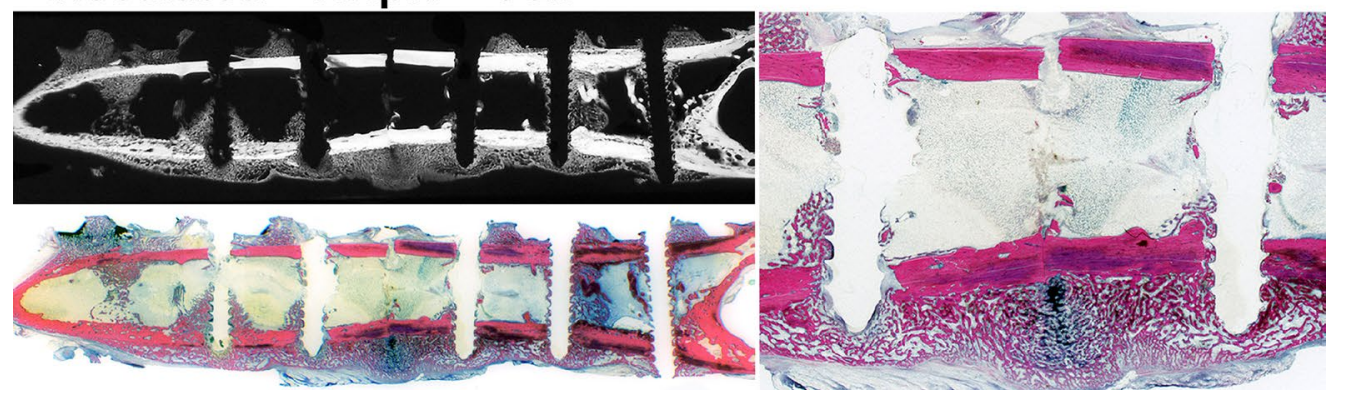

Fig. 5. Contact radiographs and Giemsa-eosin-stained overview microphotographs (left, scale bar: $10 \mathrm{~mm}$ ) of the complete operated rabbit humeri depicting the osteotomy and all six screw holes (S1-S6, 4 weeks post-operative, longitudinal cutting plane, fracture fixation implants removed, situation after mechanical testing), as well as magnified details of the humerus osteotomy site (right, scale bar: $2 \mathrm{~mm}$ ) including the two adjacent screw holes (S3, left and S4, right). 
the chance to detect any deleterious effects due to HApN administration and/or bacterial inoculation. At this 4-week time point, rabbit humeri that received a plate fixation but no hydrogel, achieved partial healing, as expected. In the histological sections, this was observed as the formation of callus, both on the cis and trans sides of the bone, as well as periosteum around the osteotomy. A larger amount of callus was formed at the trans side in comparison with the cis site, possibly due to the presence of the fracture fixation plate, which may lead to some local stress shielding and diminished formation of callus at this site of the cortex (Sha et al., 2009; Stoffel et al., 2000).

The presence of the HApN hydrogel did not significantly affect any clinical or biological response measured in the rabbits in the absence of bacterial inoculum (including weight, CRP or WBC). Similarly, bone healing was unchanged after application of the hydrogel in terms of relative stiffness of the bone in comparison to unexposed controls. Callus formation was observed at both the cis and trans side of the humerus, although the amount of callus formed at the cis side, where the HApN hydrogel was injected as a flowable solution, was slightly smaller than observed in the non-inoculated control group. Although degradation of HA in mammals usually takes from $12 \mathrm{~h}$ up to several days depending on the anatomical location (Laurent and Fraser, 1992), conjugation of moieties to the HA dimer and HA conjugates crosslinking may alter its degradation behaviour (Leone et al., 2012) and prolong its presence in vivo (Holloway et al., 2014) and the release of entrapped drugs from HA hydrogels (Purcell et al., 2014). For instance, chemically crosslinked methacrylated hyaluronan hydrogels, with increasing crosslink density and decreased enzymatic degradation rate in vitro, delay bone healing in vivo (Patterson et al., 2010). The HA formulation used in this in vivo study was rendered thermo-responsive by poly $(\mathrm{N}$ isopropylacrylamide) ( $\mathrm{pN}$ ) grafts. Moderate chain length $\mathrm{pN}$, as the $20 \mathrm{kDa}$ grafts used in this in vivo study, does not decrease cell viability in vitro (Mellati et al., 2016). The occurrence of moderate amounts of mono- and multi-nucleated histiocytes, that are part of the reticuloendothelial system and have a phagocytic function, at locations where the hydrogel was applied, suggested the presence of remnants of the HApN hydrogel and an incomplete and ongoing resorption of the HApN hydrogel 4 weeks postapplication. This, in turn, might explain the trend for slightly less callus formation at the side where the HApN was applied.

In contrast to the non-inoculated groups, rabbits receiving the bacterial inoculum, but not the gentamicin-loaded HApN, displayed no bone formation in radiographic or histological evaluation. The cause of the impaired bone regeneration might be the inflammatory reaction associated with staphylococcal infection that leads to a disruption of the homeostatic balance of bone matrix production and resorption, resulting in bone loss (Henderson and Nair, 2003; Matsuo and Irie, 2008). Furthermore, in these rabbits, the soft tissue near the osteotomy showed acellular necrotic debris and a mixed population of inflammatory cells due to inflammation below the plate, which was not observed in the inoculated rabbits that were treated with the gentamicin-loaded HApN hydrogel. Rabbits in the inoculated group without gentamicin-loaded HApN hydrogel are expected to develop an infected nonunion (Arens et al., 2015).

Rabbits that were inoculated, but received the gentamicin-loaded HApN were completely culturenegative, confirming earlier findings at week 1 (ter a

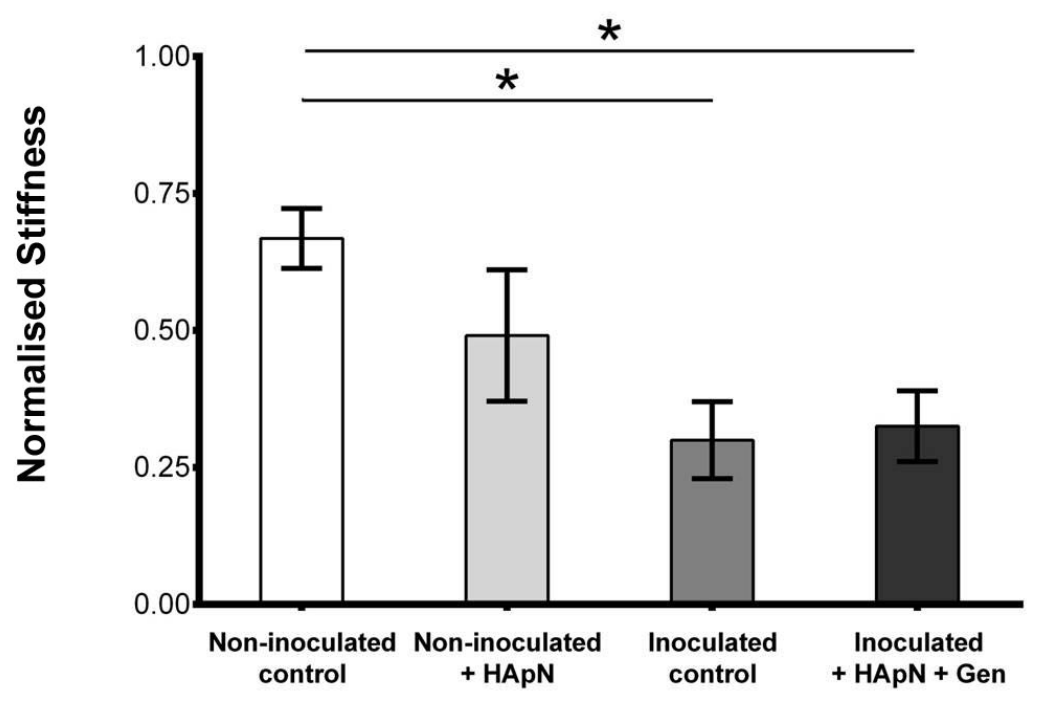

b

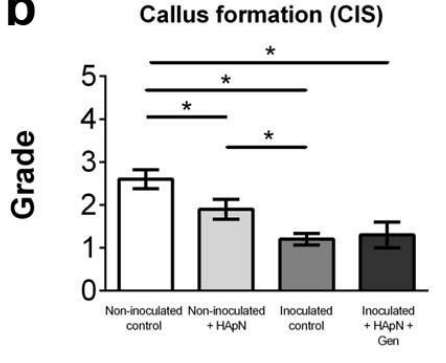

Callus formation (TRANS)

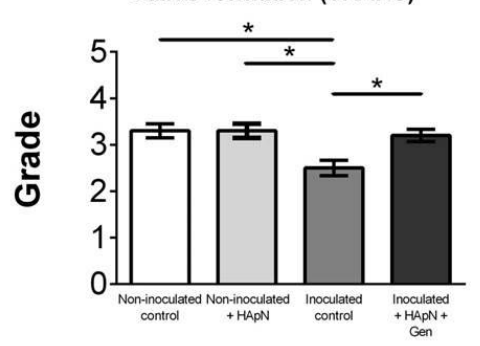

Fig. 6. Results of (a) mechanical testing by four-point bending test of operated and contralateral humeri and (b) of histopathological scoring for new callus formation, at the cis and at the trans site of the humerus. Data are represented as mean \pm standard error. ${ }^{*}$ represents significance between groups. 
Boo et al., 2016). Although S. aureus is one of the most common species involved in trauma and orthopaedic infections, bacterial mixtures are encountered as well and could be used in future in vivo studies to challenge the performance of tested ALBs. A large amount of new callus had formed at the trans site of the humerus in these rabbits, which was greater when compared with humeri from the inoculated rabbits not receiving gentamicin-loaded HApN. In the mechanical testing data, the limited callus formation at the cis side of the humerus concealed this difference in healing status. At the site where the gentamicin-loaded hydrogel was applied, large numbers of mono- and multi-nucleated histiocytes

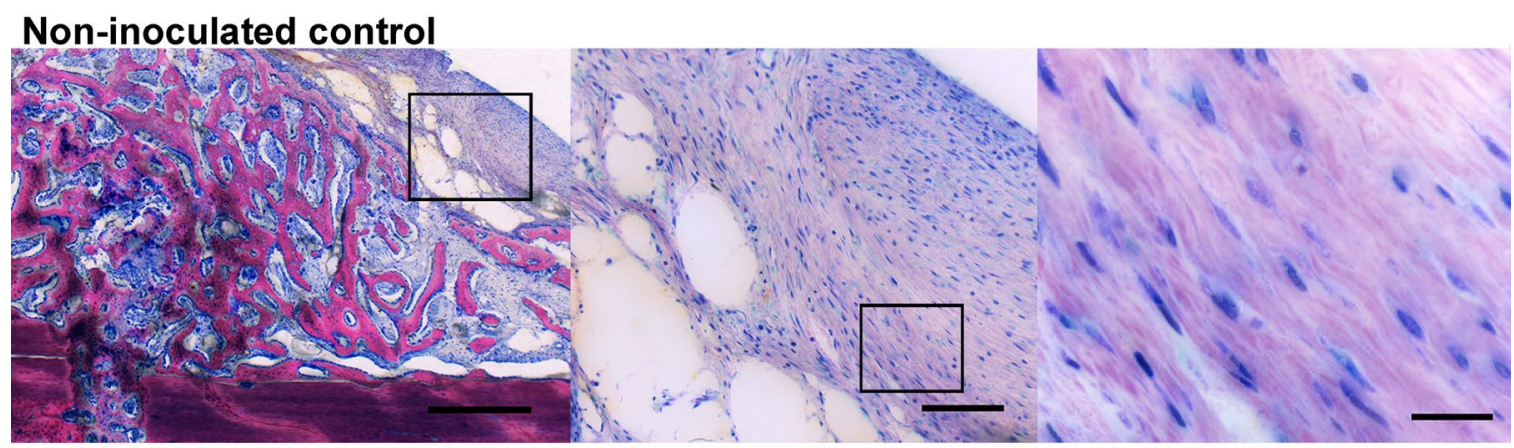

\section{Non-inoculated + HApN}

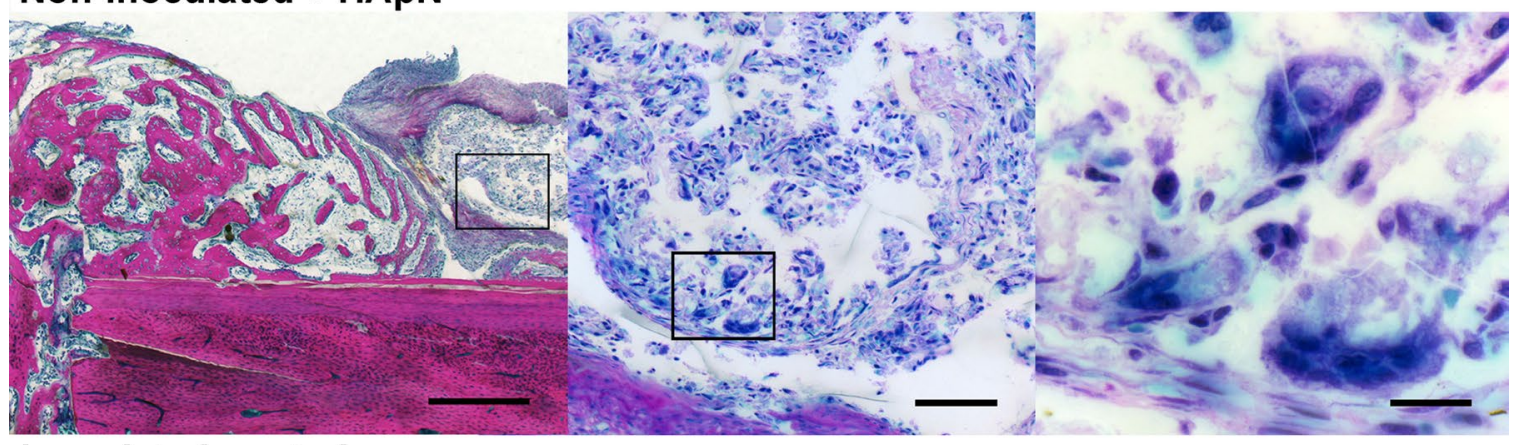

\section{Inoculated control}

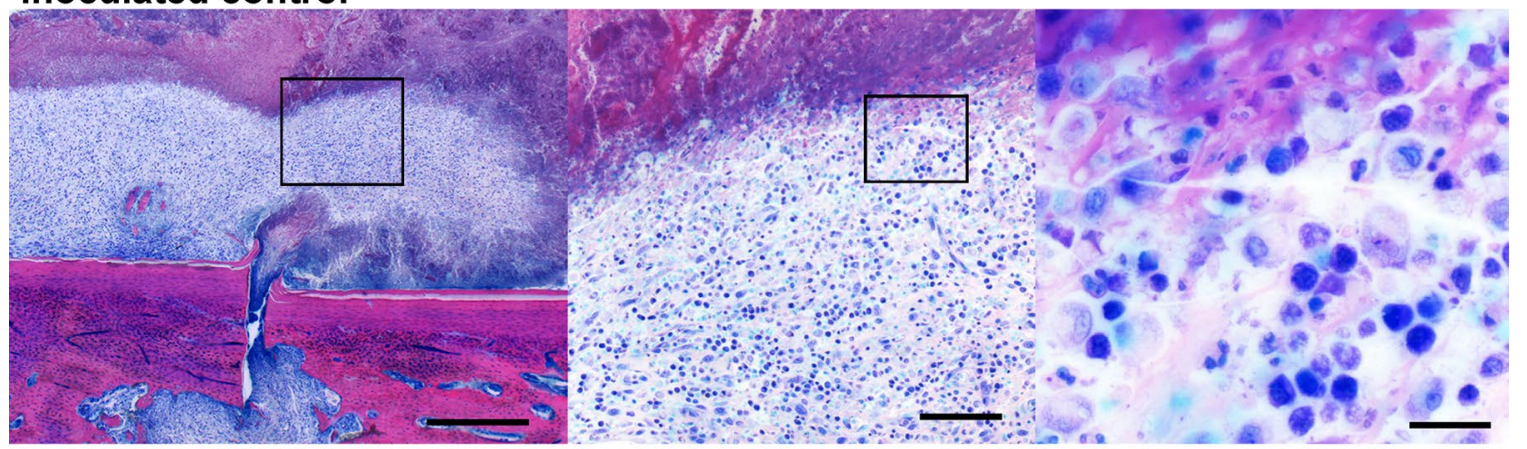

\section{Inoculated + HApN + Gen}

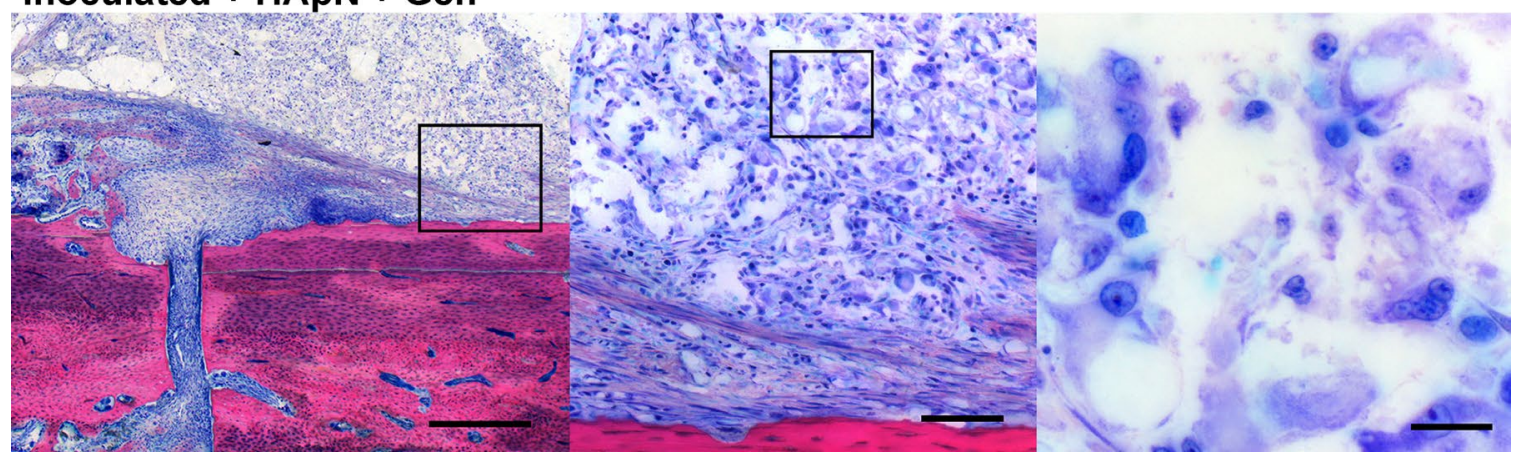

Fig. 7. Microphotographs of Giemsa-eosin-stained sections of rabbit humeri at the cis site of the osteotomy site (left column, scale bar: $500 \mu \mathrm{m}$ ), cellular details of the tissues below the plate (marked by black frames) are shown (middle column, scale bar: $100 \mu \mathrm{m}$; right column, scale bar: $20 \mu \mathrm{m}$ ). No callus formation was recorded in the inoculated control group, which instead showed necrosis and a mixedcellular inflammation. The two HApN-treated groups (with and without gentamicin) showed formation of multinucleated histiocytes with foamy bluish cytoplasm. 
were observed, suggesting ongoing HApN clearance, similar to the non-inoculated rabbits that had only received the HApN hydrogel.

Although these rabbits were infection-free, large numbers of dead bacteria might remain in the inoculated area, as the bacterial load in this study was high $\left(2 \times 10^{6} \mathrm{CFU}\right)$. Surface-associated material from dead $S$. aureus contaminants might still have the potential to upregulate osteoclast activity (Meghji et al., 1998; Nair et al., 1997). In mice, this surface-associated material from $S$. aureus cell wall preparations stimulates the production of tumour necrosis factor (TNF) $\alpha$ and interleukin (IL)-6, leading to increased bone resorption and osteoclast formation (Takeuchi et al., 2000; Takeuchi et al., 1999). High local antibiotic concentrations could potentially also decrease cell viability in the exposed locations and impair the healing process. Whereas in vitro osteoblast viability is lowered by high concentrations of aminoglycosides, such as gentamicin, when exposure takes place over an extended time (Isefuku et al., 2003; Rathbone et al., 2011), such an effect is not necessarily observed in vivo (Haleem et al., 2004).

Furthermore, the gentamicin-loaded HApN hydrogel did not show any negative systemic effect, considering that systemic gentamicin levels $3 \mathrm{~h}$ post-operatively were low and the CRP levels and WBC count in the plasma of these rabbits were comparable to the values observed in the non-inoculated rabbits, A limitation of this study was the lack of information concerning the local gentamicin concentrations, even if a rapid in vitro gentamicin release from the HApN is reported (ter Boo et al., 2016). The local concentration of gentamicin at the surgical site could also have an influence on the fate of the tissue. Therefore, in future experiments, a drain could be used to collect fluid from the surgical site in order to quantify the amount of antibiotic present over time. In the long term, fracture healing is anticipated in the rabbits treated with the gentamicin-loaded HApN hydrogel. After clearance of the high bacterial load, callus formation was observed, which would eventually bridge the osteotomy. A potential option to enhance the bone healing process could consist of the addition of osteopromotive factors (Doty et al., 2014; Mantripragada and Jayasuriya, 2016; Strobel et al., 2011; Suzuki et al., 2006).

\section{Conclusions}

In this in vivo fracture model, including osteotomy, plate fixation and bacterial inoculum, the gentamicinloaded HApN hydrogel was successful in preventing an infection. Although the model represented a close simulation of fracture healing after trauma, two questions were not addressed: the presence of other relevant or multiple pathogens and the application of the hydrogel loaded with another antibiotic at a later stage upon inoculation in order to assess the possibility of killing intracellular bacteria.
Bone formation was not significantly hindered by application of the HApN hydrogel itself, as could be seen from the mechanical testing results, as well as from the stained humeri sections. The HApN hydrogel itself did not evoke any systemic response, as was shown by the absence of differences in haematological values between the rabbits that were only operated and the rabbits that were additionally injected with the HApN hydrogel. In the S. aureusinoculated group receiving the HApN hydrogel with gentamicin, additional factors, such as the presence of dead bacteria, might have retarded bone healing. However, in the long term, in the inoculated areas where the infected humeri showed much necrosis and an absence of callus formation, it is to be expected that the humeri of the inoculated rabbits treated with the gentamicin-loaded HApN hydrogel would heal. Thus, the thermo-responsive HApN hydrogel was an effective delivery system for prophylactic antibiotics that did not affect fracture healing itself.

\section{Acknowledgements}

The authors would like to thank Dr med. vet. Stephan Zeiter and Dr med. vet. Daniel Arens for assistance during the planning and execution of the rabbit surgeries, Iris Keller for assisting with the bacteriology work, Nora Goudsouzian and Mauro Bluvol for preparing the histological sections (all from the AO Research Institute Davos, Davos, Switzerland). Dr Wouter Potters (Amsterdam Medical Centre, Amsterdam, the Netherlands) is thanked for his support with the schematic image displaying the general set-up for performing the 4-point bending test. Prof. Dr Laurent Decosterd (Laboratory of Clinical Pharmacology, University Hospital Lausanne, Lausanne, Switzerland) is thanked for performing the immuno-assay to quantify gentamicin in the rabbit plasma. This work was funded as part of the AOTrauma Clinical Priority Program Bone Infection (Grant \# AR2010_07).

\section{References}

Ambrose CG, Gogola GR, Clyburn TA, Raymond AK, Peng AS, Mikos AG (2003) Antibiotic microspheres: preliminary testing for potential treatment of osteomyelitis. Clin Orthop Relat Res 415: 279-285.

Arens D, Wilke M, Calabro L, Hackl S, Zeiter S, Zderic I, Richards RG, Moriarty TF (2015) A rabbit humerus model of plating and nailing osteosynthesis with and without Staphylococcus aureus osteomyelitis. Eur Cell Mater 30: 148-162.

Aya KL, Stern R (2014) Hyaluronan in wound healing: rediscovering a major player. Wound Repair Regen 22: 579-593.

Bellini D, Topai A (2000) Amides of hyaluronic acid and the derivatives thereof and a process 
for their preparation. Patent application number CA2339066A1.

Boxma H, Broekhuizen T, Patka P, Oosting H (1996) Randomised controlled trial of single-dose antibiotic prophylaxis in surgical treatment of closed fractures: the Dutch trauma trial. Lancet 347: 11331137.

Campoccia D, Montanaro L, Moriarty TF, Richards RG, Ravaioli S, Arciola CR (2008) The selection of appropriate bacterial strains in preclinical evaluation of infection-resistant biomaterials. Int J Artif Organs 31: 841-847.

D'Este M, Alini M, Eglin D (2012) Single step synthesis and characterization of thermoresponsive hyaluronan hydrogels. Carbohydr Polym 90: 13781385.

D'Este M, Sprecher CM, Milz S, Nehrbass D, Dresing I, Zeiter S, Alini M, Eglin D (2016) Evaluation of an injectable thermoresponsive hyaluronan hydrogel in a rabbit osteochondral defect model. J Biomed Mater Res A 104: 1469-1478.

Darouiche RO (2001) Device-associated infections: a macroproblem that starts with microadherence. Clin Infect Dis 33: 1567-1572.

Darouiche RO (2004) Treatment of infections associated with surgical implants. N Engl J Med 350: 1422-1429.

Doty HA, Leedy MR, Courtney HS, Haggard WO, Bumgardner JD (2014) Composite chitosan and calcium sulfate scaffold for dual delivery of vancomycin and recombinant human bone morphogenetic protein-2. J Mater Sci Mater Med 25: 1449-1459.

Ferguson JY, Dudareva M, Riley ND, Stubbs D, Atkins BL, McNally MA (2014) The use of a biodegradable antibiotic-loaded calcium sulphate carrier containing tobramycin for the treatment of chronic osteomyelitis: a series of 195 cases. Bone Joint J 96-B: 829-836.

Fraser JR, Laurent TC, Laurent UB (1997) Hyaluronan: its nature, distribution, functions and turnover. J Intern Med 242: 27-33.

Gosselin RA, Roberts I, Gillespie WJ (2004) Antibiotics for preventing infection in open limb fractures. Cochrane Database Syst Rev: CD003764.

Haleem AA, Rouse MS, Lewallen DG, Hanssen AD, Steckelberg JM, Patel R (2004) Gentamicin and vancomycin do not impair experimental fracture healing. Clin Orthop Relat Res 38: 22-24.

Henderson B, Nair SP (2003) Hard labour: bacterial infection of the skeleton. Trends Microbiol 11: $570-577$.

Holloway JL, Ma H, Rai R, Burdick JA (2014) Modulating hydrogel crosslink density and degradation to control bone morphogenetic protein delivery and in vivo bone formation. J Control Release 191: 63-70.

Isefuku S, Joyner CJ, Simpson AH (2003) Gentamicin may have an adverse effect on osteogenesis. J Orthop Trauma 17: 212-216.
ISO 9585 (1990) Preview Implants for surgeryDetermination of bending strength and stiffness of bone plates: 1-4.

Laurent TC, Fraser JR (1992) Hyaluronan. FASEB J 6: 2397-2404.

Leone G, Consumi M, Lamponi S, Magnani A (2012) New hyaluroran derivative with prolonged half-life for ophthalmogical formulation. Carbohydr Polym 88: 799-808.

Mantripragada VP, Jayasuriya AC (2016) Effect of dual delivery of antibiotics (vancomycin and cefazolin) and BMP-7 from chitosan microparticles on Staphylococcus epidermidis and pre-osteoblasts in vitro. Mater Sci Eng C Mater Biol Appl 67: 409-417.

Matsuo K, Irie N (2008) Osteoclast-osteoblast communication. Arch Biochem Biophys 473: 201-209.

McLaren JS, White LJ, Cox HC, Ashraf W, Rahman CV, Blunn GW, Goodship AE, Quirk RA, Shakesheff KM, Bayston R, Scammell BE (2014) A biodegradable antibiotic-impregnated scaffold to prevent osteomyelitis in a contaminated in vivo bone defect model. Eur Cell Mater 27: 332-349.

Meghji S, Crean SJ, Hill PA, Sheikh M, Nair SP, Heron K, Henderson B, Mawer EB, Harris M (1998) Surface-associated protein from Staphylococcus aureus stimulates osteoclastogenesis: possible role in $S$. aureus-induced bone pathology. Br J Rheumatol 37: 1095-1101.

Mellati A, Valizadeh Kiamahalleh M, Dai S, Bi J, Jin B, Zhang H (2016) Influence of polymer molecular weight on the in vitro cytotoxicity of poly (N-isopropylacrylamide). Mater Sci Eng C Mater Biol Appl 59: 509-513.

Metsemakers WJ, Handojo K, Reynders P, Sermon A, Vanderschot P, Nijs S (2015) Individual risk factors for deep infection and compromised fracture healing after intramedullary nailing of tibial shaft fractures: a single centre experience of 480 patients. Injury 46: 740-745.

Moriarty TF, Campoccia D, Nees SK, Boure LP, Richards RG (2010) In vivo evaluation of the effect of intramedullary nail microtopography on the development of local infection in rabbits. Int J Artif Organs 33: 667-675.

Nair SP, Meghji S, Wilson M, Nugent I, Ross A, Ismael A, Bhudia NK, Harris M, Henderson B (1997) Clinical isolates of Staphylococcus aureus have osteolytic surface proteins and a proportion of the population have antibodies that block this activity: is this of prognostic significance?. Br J Rheumatol 36: 328-332.

Oh EJ, Park K, Kim KS, Kim J, Yang JA, Kong JH, Lee MY, Hoffman AS, Hahn SK (2010) Target specific and long-acting delivery of protein, peptide, and nucleotide therapeutics using hyaluronic acid derivatives. J Control Release 141: 2-12.

Patterson J, Siew R, Herring SW, Lin AS, Guldberg R, Stayton PS (2010) Hyaluronic acid hydrogels with controlled degradation properties for oriented bone regeneration. Biomaterials 31: 6772-6781. 
Peng KT, Chen CF, Chu IM, Li YM, Hsu WH, Hsu RW, Chang PJ (2010) Treatment of osteomyelitis with teicoplanin-encapsulated biodegradable thermosensitive hydrogel nanoparticles. Biomaterials 31: 5227-5236.

Purcell BP, Kim IL, Chuo V, Guinen T, Dorsey SM, Burdick JA (2014) Incorporation of sulfated hyaluronic acid macromers into degradable hydrogel scaffolds for sustained molecule delivery. Biomater Sci 2: 693-702.

Rathbone CR, Cross JD, Brown KV, Murray CK, Wenke JC (2011) Effect of various concentrations of antibiotics on osteogenic cell viability and activity. J Orthop Res 29: 1070-1074.

Sha M, Guo Z, Fu J, Li J, Yuan CF, Shi L, Li SJ (2009) The effects of nail rigidity on fracture healing in rats with osteoporosis. Acta Orthop 80: 135-138.

Stewart RL, Cox JT, Volgas D, Stannard J, Duffy L, Waites KB, Chu TM (2010) The use of a biodegradable, load-bearing scaffold as a carrier for antibiotics in an infected open fracture model. J Orthop Trauma 24: 587-591.

Stoffel K, Klaue K, Perren SM (2000) Functional load of plates in fracture fixation in vivo and its correlate in bone healing. Injury 31 Suppl 2: S-B37-50.

Strobel C, Bormann N, Kadow-Romacker A, Schmidmaier G, Wildemann B (2011) Sequential release kinetics of two (gentamicin and BMP-2) or three (gentamicin, IGF-I and BMP-2) substances from a one-component polymeric coating on implants. J Control Release 156: 37-45.

Suzuki A, Terai H, Toyoda H, Namikawa T, Yokota Y, Tsunoda T, Takaoka K (2006) A biodegradable delivery system for antibiotics and recombinant human bone morphogenetic protein-2: A potential treatment for infected bone defects. J Orthop Res 24: 327-332.

Takeuchi O, Hoshino K, Akira S (2000) Cutting edge: TLR2-deficient and MyD88-deficient mice are highly susceptible to Staphylococcus aureus infection. J Immunol 165: 5392-5396.

Takeuchi O, Hoshino K, Kawai T, Sanjo H, Takada H, Ogawa T, Takeda K, Akira S (1999) Differential roles of TLR2 and TLR4 in recognition of gramnegative and gram-positive bacterial cell wall components. Immunity 11: 443-451.

ter Boo GJ, Arens D, Metsemakers WJ, Zeiter S, Richards RG, Grijpma DW, Eglin D, Moriarty TF (2016) Injectable gentamicin-loaded thermoresponsive hyaluronic acid derivative prevents infection in a rabbit model. Acta Biomater 43: 185-194.

ter Boo GJ, Grijpma DW, Moriarty TF, Richards RG, Eglin D (2015) Antimicrobial delivery systems for local infection prophylaxis in orthopedic- and trauma surgery. Biomaterials 52: 113-125.

Terjesen T (1984) Plate fixation of tibial fractures in the rabbit. Correlation of bone strength with duration of fixation. Acta Orthop Scand 55: 452-456.

Trampuz A, Zimmerli W (2006) Diagnosis and treatment of infections associated with fracturefixation devices. Injury 37 Suppl 2: S59-66.
Tripodo G, Trapani A, Torre ML, Giammona G, Trapani G, Mandracchia D (2015) Hyaluronic acid and its derivatives in drug delivery and imaging: recent advances and challenges. Eur J Pharm Biopharm 97: 400-416.

von Eiff C, Jansen B, Kohnen W, Becker K (2005) Infections associated with medical devices: pathogenesis, management and prophylaxis. Drugs 65: 179-214.

Wang XP, Zhang XL, Li ZG, Yu XG (2005) A first order system model of fracture healing. J Zhejiang Univ Sci B 6: 926-930.

\section{Discussion with Reviewers}

Anika Schumacher: What are the authors' thoughts on a model improvement: having part of the gel degrading fast, for short-term treatment with gentamicin, and another part degrading more slowly as a long-term treatment against intracellular bacteria? Which would be the first step for improving this model?

Authors: A dual release system comprising a fast degradable HApN loaded with gentamicin sulphate and a slow degradable particulate system loaded with intracellular bactericidal agent could be designed. For example, gentamicin-loaded nanoparticles of poly(lactide-co-glycolide) acid targeting intracellular bacteria are reported and can be easily dispersed in HApN (Lecaroz et al., 2006). Other improvement to the model could consist in assessing the loading and release of other antibiotics, such as cephalosporins, commonly used in prophylaxis regime for trauma patients (Zimmerli, 2007).

Anika Schumacher: Could bacteria be isolated from an infected implant, expanded and introduced in such a fracture/osteotomy model? In that case, the bacterial population could be more representative of in vivo infections than studying single pathogens. Authors: A well characterised clinical isolate of $S$. aureus sampled from an infected knee prosthesis was used in this study. Other isolated bacteria from an infected implant could be characterised, expanded and introduced into this same osteotomy model. A similar bone healing could be expected upon clearance of the bacteria by the gentamicin-loaded hydrogel.

John Daiss: Is there a way to move from burst-release of antibiotics to sustained release (or is this even desirable)?

Authors: Prolonged release of small molecules over months without burst release can certainly be achieved by using drug-loaded polymeric microcarriers dispersed into a gel (Lagarce et al., 2005). This approach is reported for the delivery of gentamicin from pegylated polylactide-co-glycolide dispersed in a chitosan hydrogel matrix (Dorati et al., 2016). Interestingly, no influence of the hydrogel on 
the in vitro gentamicin release is observed, suggesting that a sustained release of gentamicin from a hydrogel delivery system can be achieved.

Gentamicin has a concentration-dependent bactericidal effect with optimal antibacterial activity achieved at a concentration higher than its minimum inhibitory concentration and lower than its toxicity level. Therefore, a local burst release may not be detrimental and sufficient to treat an infection if the amount of released gentamicin has no harmful effect locally and systematically, as observed in our study, and permit the eradication of the local bacterial load. However, it remains unclear if such burst release profile could be sufficient to eradicate an established infection, as the half-life of gentamicin in the body is between 2.5 to $3 \mathrm{~h}$ only.

John Daiss: Is the gentamicin released in the first $24 \mathrm{~h}$ or is its release sustained over days or week?

Authors: A previous study from our group reports that, in an in vitro release test under sink conditions, HApN with $1 \% \mathrm{w} / \mathrm{w}$ gentamicin releases most of the gentamicin sulphate load during the first $24 \mathrm{~h}$ and complete depletion is achieved after $5 \mathrm{~d}$ (ter Boo GJ et al., 2016). In the same study, the systemic concentration of antibiotic measured in vivo indicates that the gentamicin concentration in the blood samples after $24 \mathrm{~h}$ drops below the detection limit of the analysis method (ter Boo GJ et al., 2016).

It is difficult to conclude if all the gentamicin was released from the biodegradable matrix or if it was still present locally. Quantifying the local gentamicin concentration in this in vivo rabbit model was not feasible, but it is conceivable that, based on the hydrophilic nature of the sulphate salt of gentamicin and the previously reported in vitro results, the antibiotic release does not last longer than a few days.

John Daiss: The clearance of the matrix was anticipated, but not clearly demonstrated in Fig. 7 . Do you have a mean for imaging the HApN matrix? Authors: Due to the nature of the HApN hydrogel matrix, a hyaluronan derivative, attempts to extract it or differentiate it from biological tissues applying specific protocols, stains or performing spectroscopic analyses (e.g. infra-red) were not successful. The labelling of the derivative with a fluorescent dye would be another possibility, but has the main drawback that it can potentially modify the degradation properties of the material. Radioactive labelling (e.g. tritium substituted for an acetyl group hydrogen atom in hyaluronic acid) is likely to be the most meaningful method (Reed et al., 1990), but at a very high price in term of cost, expertise and time. The fact that the imaging and degradation of the HApN could not be achieved was certainly a limitation of the study.

John Daiss: Is it easy to demonstrate the reduction in abundance from day 1 to day 28? Will the histiocytes involved in clearance be absent after 6 or 8 or 10 weeks?

Authors: From a previous in vivo study (Arens D et al., 2015), it is known that the created osteotomy heals in approximately 10 weeks. Intentionally, a 4-week time point was chosen to best observe the differences amongst the groups, assuming that at a later time point the differences between the non-inoculated and inoculated + treated groups would not be significant. The presence of histiocytes at 4 weeks indicated an active removal of foreign bodies, namely the bacterial load and the antibiotic delivery system; however, the overall healing process was only mildly affected. A longer study with a final time point at 10 weeks would need to be performed to assess the reduction and absence of histiocytes and normalisation of the healing process.

\section{Additional References}

Dorati R, DeTrizio A, Genta I, Grisoli P, Merelli A, Tomasi C, Conti B (2016) An experimental design approach to the preparation of pegylated polylactideco-glycolide gentamicin loaded microparticles for local antibiotic delivery. Mater Sci Eng C Mater Biol Appl 58: 909-917.

Lagarce F, Faisant N, Desfontis JC, Marescaux L, Gautier F, Richard J, Menei P, Benoit JP (2005) Baclofen-loaded microspheres in gel suspensions for intrathecal drug delivery: in vitro and in vivo evaluation. Eur J Pharm Biopharm 61: 171-180.

Lecaroz C, Gamazo C, Blanco-Prieto MJ (2006) Nanocarriers with gentamicin to treat intracellular pathogens. J Nanosci Nanotechnol 6: 3296-3302.

Reed RK, Laurent UB, Fraser JR, Laurent TC (1990) Removal rate of [3H] hyaluronan injected subcutaneously in rabbits. Am J Physiol Heart Circ Physiol 259: H532-5.

Zimmerli W (2007) Antibiotic prophylaxis. AO principles of fracture management. TP Rüedi, RE Buckley, CG Moran (Eds.), AO Publishing, Davos Platz, pp: 425-433.

Editor's notes: The Scientific Editor responsible for this paper was Joost de Bruijn. 